\title{
TEATP
}

УДК 792.09 (73):82-25

\section{Ю.А. Клейман}

\section{ТЕАТР «ПРОВИНСТАУН ПЛЕЙЕРС» И ГЕНЕЗИС ЖЕНСКОЙ ДРАМАТУРГИИ В США}

Российский государственный институт сценических искусств,

Российская Федерация, 191028, Санкт-Петербург, ул. Моховая, 34

Анализируется специфика деятельности и социокультурное значение американского театра «Провинстаун плейерс», чье недолгое существование оказало огромное влияние на развитие творческого метода Юджина О'Нила. Практика театра рассматривается в контексте становления «новой драмы», с одной стороны, и появления суфражизма - с другой. В выбранном ракурсе, сущностном для понимания той роли, которую театр сыграл в истории американской культуры, деятельность «Провинстаун плейерс»ранее в российском театроведении не освещалась. Подробно разбирается никогда не переводившаяся на русский язык пьеса Сьюзан Гласпелл «Мелочи». Впервые в научной традиции выявляется близость драматургии Гласпелл европейской «новой драме», ее сценический потенциал, а также мотивы, которые в дальнейшем найдут воплощение не только в ранней, но и в зрелой драматургии Юджина О’Нила, что позволяет пересмотреть степень влияния театра «Провинстаун плейерс» на творчество ведущего драматурга США первой половины XX в. Библиогр. 15 назв.

Ключевые слова: Сьюзан Гласпелл, театр «Провинстаун плейерс», драматургия США, американский театр, пьеса «Мелочи», Юджин О’Нил.

\section{THE PROVINCETOWN PLAYERS THEATRE AND THE GENESIS OF WOMEN PLAYWRIGHTS IN THE USA}

\section{Yu. A. Kleiman}

Russian State Institute of Performing Arts, 34, Mokhovaya st., St. Petersburg, 191028, Russian Federation

The article analyzes the specifics of the activity and the sociocultural significance of the American Provincetown Players theatre, whose brief existence had an enormous influence on the formation of Eugene O'Neill's creative method. The theatre's practice is examined on one hand within the context of the formation of the 'New Drama', and within that of the appearance of the Women's Suffrage movement on the other. It has never previously been examined from this viewpoint, so essential for an understanding of the role it played in the history of American culture. The article analyzes in detail Susan Glaspell's play Trifles, which has never been translated into Russian. For the first time in the academic tradition, the closeness of Glaspell's plays to European 'New Drama' and their scenic potential are revealed, as well as the motifs present in them that would later become manifest both in the early and mature plays of Eugene O'Neill. This allows us to take another look at the level of influence that the Provincetown Players had on the leading playwright of the United States of the first half of $20^{\text {th }}$ century. Refs. 15.

Keywords: Susasn Glaspell, Provincetown Players theatre, playwrights in the USA, American theatre, play Trifles, Eugene O’Neill.

(C) Санкт-Петербургский государственный университет, 2017 
Столетие назад в американском театре произошла самая настоящая революция. У Бродвея с его приверженностью натурализму и коммерческой устремленностью появилась альтернатива. Гораздо позднее появятся офф-Бродвей и офф-оффБродвей, ЛаМама и Нью-Йорк Тиэтр Воркшоп. Но именно тогда, во второй декаде XX в., в США впервые возник интерес к театру как к искусству, таящему огромные возможности не только художественной, но и социальной самореализации.

Первое десятилетие XX в. - время жадного интереса американцев к европейским новациям. В 1911 г. в США опубликована книга Гордона Крэга «Искусство театра», провозглашавшая необходимость изгнания с подмостков традиции копирования жизни. Тогда же Йейтс прочел американским студентам лекцию о творчестве Крэга. Американских зрителей удивляли Элеонора Дузе, ирландский «Эбби тиэтр», «Русские сезоны» Сергея Дягилева, «Сон в летнюю ночь» англичанина Харви Гренвилл-Баркера, «Сумурун» немецкого режиссера Макса Рейнхардта, «Проделки Скапена» француза Жака Копо. Спустя десятилетие Константин Станиславский заявит, что американцы «видели все лучшее, что есть в Европе» [1, с.81].

Эти события спровоцировали появление так называемых «малых театров». Большинство из них было любительскими кружками, арендовавшими крошечные помещения. Их участники ставили перед собой амбициозную задачу создания национального театра на новых основаниях: то, что молодой театр в США уже нуждается в обновлении, было очевидно всем. Первый «малый театр» появился в 1912 г., к 1917-му таких театров было уже 50. В противовес бродвейским коммерческим стандартам участники «малых театров» обращались к постановке европейской «новой драмы» и античной драматургии, большинство опытов носило символистский характер. Театры ставили преимущественно А. Стриндберга, Х. Ибсена, М. Метерлинка, А. Чехова. С собственной «новой драмой» дела обстояли сложнее, в основном к соотечественникам-драматургам относились с подозрением. Так, театр «Вашингтон сквер плейерс» с весьма категоричной формулировкой отказался взять в работу пьесу Ю. О’Нила.

В настоящий момент в США существует около двадцати одних только университетских магистерских программ по драматургии. Помимо этого, целый ряд лабораторий помогает авторам довести свои пьесы до совершенства. В США 1910-х годов такой драматургической лабораторией, где любой начинающий автор мог увидеть свою пьесу поставленной, стал театр «Провинстаун плейерс».

Театр получил свое название благодаря курортному местечку в штате Массачусетс: именно Провинстаун был летней резиденцией богемы, в холодные месяцы обитавшей в нью-йоркском районе Гринвич-Вилладж. За семь лет существования «Провинстаун плейерс» поставил девяносто три пьесы сорока семи авторов. Более трети этих пьес было написано женщинами-драматургами, что было совсем невероятно для этой эпохи. Театр вошел в историю прежде всего премьерами пьес Юджина О’Нила «Император Джонс» (1920) и «Косматая обезьяна» (1922). Но трудно переоценить и его роль для развития феномена американской женской драматургии.

Женщины играли в деятельности «Провинстаун плейерс» весьма значительную, если не решающую роль. Они писали пьесы, занимались финансами, отбирали материал для постановок, ставили, оформляли спектакли и исполняли роли (см.: [2]). Излишне говорить, что все женщины, группировавшиеся вокруг 
«Провинстаун плейерс», обладали редкой на ту пору привилегией - высшим образованием - и многие из них были членами первых в Америке феминистских организаций, таких как «Женский профсоюз», «Женская суфражистская партия Нью-Йорка», «Еретички». Именно театр дал им совершенно новые возможности для реализации творческого потенциала, а кроме того, стал трибуной для обсуждения самых острых вопросов современности. Репертуар составляли одноактные пьесы (вполне в духе «новой драмы»), которые позволяли драматургам-дилетантам заявить проблему, не утруждая себя ее разработкой. Магистральная тема несправедливость патриархального мироустройства, в котором женщине отводится подчиненная, унизительная роль. Заявлялись такие темы, как несостоятельность института брака («Вдовья вуаль» Эллис Ростеттер, «Зимняя ночь» Нет Бойс), лживость общественной морали («Существо из ребра» Риты Веллман, «Женская честь» Сьюзан Гласпелл), двойные стандарты («Постоянство»Нет Бойс), невозможность сочетать материнство и карьеру («Он и она» Рэйчел Крозерс, «На краю» Сьюзан Гласпелл), способность женщины играть активную роль в общественной жизни («Доносчик» Мэри Фостер Барбер), женская солидарность («Детская коляска» Босворт Крокер), материнство, которое может стать тяжким бременем («Фуникули-фуникула» Риты Веллман, «Два сына» Нет Бойс), необходимость контроля рождаемости («Цепи чистоты» Сьюзан Гласпелл).

Многие из участниц «Провинстаун плейерс» были счастливы в браке и имели детей, но они ставили перед собой принципиальную задачу: разбить викторианский стереотип хранительницы домашнего очага, показать, что домохозяйка не единственная возможная для женщины роль (см.: [3, p.18]), а мужчина - не единственный властитель жизни, и он отнюдь не обладает презумпцией невиновности. Нельзя не увидеть здесь новый уровень обсуждения проблем, заявленных Хенриком Ибсеном и Бернардом Шоу. Эту тоску по самореализации женщины рубежа веков воплотил в романе «Главная улица» Синклер Льюис. К 1920 г., моменту написания романа, эмансипация женщин все больше становилась реальностью.

Формальное лидерство в «Провинстаун плейерс» принадлежало Джорджу Крэму Куку. Склонный к теоретизированию, восторженный ницшеанец Кук обосновал концепцию театра - открытой сцены, где ни один драматург не будет отвергнут. Правило театра гласило: «Ни одна пьеса не будет рассмотрена, если автор не будет контролировать ее постановку. <...> Автор должен ставить пьесу без каких-либо преград, в соответствии со своими собственными идеями» (цит. по: [4, р. 39]).

Однако реально ключевая роль в «Провинстаун плейерс», особенно на первых порах, принадлежала его жене - талантливому прозаику и драматургу Сьюзан Гласпелл, автору одиннадцати пьес (две из них в соавторстве с Куком). Разнообразные жанрово и тематически, пьесы Сьюзан Гласпелл лишь с 1970-1980-х годов стали предметом изучения американских ученых (на волне нового интереса к феминизму), однако в 1910-е годы именно ее талант в сочетании с активной жизненной позицией сделал «Провинстаун плейерс» Меккой для художественно одаренных «новых женщин»: в лице Гласпелл они получали вдохновение и поддержку.

История театра началась с того, что Кук и Гласпелл вместе написали пьесу «Подавленные желания», которая остроумно пародировала всеобщее увлечение психоанализом. Герои - Хенриетта и Стивен Брюстер (Brewster). Он - архитектор, 
она - суфражистка, восторженная почитательница психоанализа. Она доводит своего мужа до умопомрачения, подозревая во всех его действиях подавленные желания. Хенриетта требует, чтобы Стивен рассказывал ей все свои сны и постоянно посещал консультации психоаналитика Руссела. У четы гостит сестра Хенриетты Мейбл - наивная буржуазная дамочка, которая вполне счастлива в браке. Однако Хенриетта пытается «разоблачить» и ее. Последствия едва не оказываются для Хенриетты роковыми. Во сне Мейбл видит себя курицей и слышит, как ей говорят: «Шагай, курица» («Step, Hen»). Хенриетта видит в этом знак увлечения Мейбл другом семьи Эгглстоном (Egg - яйцо) и убеждает ее бросить мужа. Однако доктор Руссел ставит другой диагноз. Сон Стивена об исчезающих стенах он трактует как его подсознательное желание расторгнуть брак с Хенриеттой, а сон Мейбл - как подавленное влечение к Стивену: если соединить слова Step и Hen, получится... Стивен (Stephen), фамилию же четы Brewster психоаналитик трактует как «Будь моим петухом» («Be my rooster»). Подобные подавленные желания Хенриетту совсем не радуют, и она решает завязать с психоанализом: «Я сожгу журнал “Патологический психоанализ”» $[5, \mathrm{p} .51]$.

Театр «Вашингтон сквер плейерс» отверг пьесу как слишком «специфичную». Пройдет десятилетие, и «специфичная» пьеса будет широко ставиться по всей стране. Но тогда, в 1915 г., литераторы Гласпелл и Кук решили поставить ее собственными силами. Писательница Нет Бойс предоставила для премьерной постановки гостиную своего дома и снабдила вечер собственной пьесой «Постоянство». В «Постоянстве» после разрыва встречались бывшие любовники Мойра и Рэкс. Рэкс артикулировал сугубо маскулинную точку зрения на отношения между мужчиной и женщиной: неверный возлюбленный требовал от Мойры верности - «постоянства», оставляя себе право на мимолетные увлечения. Героиня же - истинная «новая женщина» - заявляла, что не желает «возглавлять гарем» [6, p. 61].

Никакого специального светового оборудования в гостиной, где разворачивался первый в истории «Провинстаун плейерс» спектакль, разумеется, не было. Но начинающий сценограф Роберт Эдмонд Джонс создал подобие световой партитуры, изобретательно поставив «свечу здесь, лампу там» [7, р. 251]. Небольшое пространство гостиной он организовал таким образом, что зрители вначале следили за словесными баталиями героев пьесы «Постоянство», которые проходили на балконе (в качестве задника был настоящий океанский залив), а потом разворачивались и вместе с героями пьесы «Подавленные желания» оказывались в заваленном чертежами и книгами кабинете архитектора. Гласпелл и Кук, которым в этот вечер предстояло дебютировать еще и в качестве актеров, нервничали как никогда. Чтобы хоть как-то успокоиться, они сказали друг другу перед спектаклем, взявшись за руки: «Ничего, это скоро закончится» [7, р. 259].

Но все только началось. Этот вечер стал первым в истории театра «Провинстаун плейерс». Оказалось, что желающих побывать на постановках новых американских пьес куда больше, чем может вместить гостиная. Тем же летом 1915 г. Кук арендовал рыболовецкий сарай. Зрители приходили в крошечный деревянный театр на набережной все лето, и по завершении сезона Куку не составило труда найти подписчиков на следующий год. Вдохновленный успехом, Кук поспешил анонсировать премьеру новой пьесы Гласпелл - пьесы, даже замысла которой еще не существовало. Сьюзан Гласпелл заявила мужу, что никогда не изучала драматургию и не 
знает, как писать, на что он парировал, что теперь у них есть сцена, а это - самое главное.

Сьюзан Гласпелл вняла его совету. Она приходила в театр на пристани, подолгу сидела на скамейке и вглядывалась в сцену, пока перед ее мысленным взором «сцена не превратилась в кухню». Гласпелл явственно представила, как «люди группой появляются через заднюю дверь - двое или трое мужчин... и две женщины, которые пятятся, неохотно входя на эту кухню» [7, р.256]. Не имея опыта работы в театре, Сьюзан Гласпелл создавала пьесу дома за письменным столом, но приходила проверять действия персонажей театральной площадкой и нещадно вычеркивала сцены, не прошедшие проверку. Через десять дней состоялась читка, и пьеса «Мелочи» (“Trifles”) была принята к постановке.

Дебют Сьюзан Гласпелл (это была ее первая самостоятельная пьеса) оказался настолько удачен, что драму не только до сих пор ставят, но и включают в антологию лучших американских пьес, а в 2010 г. по ее мотивам была создана опера на музыку композитора Джона Г. Билотты.

В качестве сюжета писательница взяла случай, с которым она в юности столкнулась, работая газетным репортером: убийство фермера, предположительно совершенное его женой. Предположительно, потому что женщина была арестована и долгое время провела в тюрьме, но ее виновность так и не была доказана, впрочем, и обвинение снято не было. Знаменательно, что двумя годами раньше пьесой «Суд», являющейся драматизированным судебным процессом об убийстве, дебютировал еще один известный американец - драматург Элмер Райс. Сюжетом для пьесы ему также послужил случай из собственной адвокатской практики.

Пьеса «Мелочи» открывается приходом в дом жертвы убийства окружного прокурора, а также шерифа и соседа с их супругами. Когда-то молодая корреспондентка Гласпелл была на месте своих персонажей, входя в чужую кухню, чтобы собрать материал для статьи. Теперь она вышла на сцену в роли соседки - миссис Хейл. Сама по себе кухня, эта исконная женская обитель, которая предстает посетителям в жалком, убогом виде, оказывается красноречивее любых судебных речей (см.: [8, p. 35]). По справедливому замечанию исследовательницы В. Маковски, «унылая, холодная и находящаяся в беспорядке кухня» пьесы Гласпелл разрушает американский миф о домашнем очаге как символе «нравственности, порядка, комфорта и взаимопонимания» [9, р.51].

Мужчины приходят для того, чтобы найти улики, изобличающие мотив преступления, женщины - для того чтобы собрать для арестованной ее вещи. Из диалога выясняется, что Джон Райт был найден в своей кровати задушенным веревкой, а его жена утверждала (что, разумеется, совершенно неправдоподобно), что ничего не слышала, производя при этом впечатление маловменяемой женщины. Это завязка пьесы, после которой мужчины уходят на второй этаж, чтобы внимательно изучить спальню, а женщины остаются, чтобы из пустяков, «мелочей» соткать на наших глазах ту житейскую паутину, в которой запуталась совершившая убийство женщина. Ни убийца, ни убитый на сцене так и не появятся. Но благодаря находкам и разговорам миссис Хейл и миссис Петерс зрители живо представят себе, как в течение многих лет Минни Райт вела жизнь одинокую и унылую.

Насильственная смерть - распространенный мотив американской литературы 1910-1920-х годов (помимо драматургии вспомним «Американскую трагедию» 
Т.Драйзера). Однако в пьесе Гласпелл отнюдь не убийство является источником драматизма. Оно происходит некогда раньше, случается за пределами пьесы и является лишь поводом к вскрытию иной, главной, темы. Важно, что именно толкнуло героиню к убийству, а это - тот самый провозглашенный Морисом Метерлинком трагизм повседневности: ежедневное угасание в женщине витальной энергии в то время, как ее жизнь протекала в обычном доме рядом с обычным мужчиной.

Трагизм повседневности вырисовывается в пьесе благодаря точно подобранным деталям - тем самым «мелочам». Создавая пьесу как прообраз непременного спектакля (ведь заранее было известно, где, кем и как он будет подготовлен и сыгран), Гласпелл вступала в полемику с бродвейским мейнстримом, который ей был хорошо известен. На нью-йоркских подмостках царил драматург и режиссер Дэвид Беласко. В его мелодрамах сцена была завалена множеством не несущих смысловой нагрузки предметов, которые должны были создавать натуралистический «срез жизни».

Сьюзан Гласпелл, как это свойственно авторам «новой драмы», обширными ремарками выстраивает в пьесе изобретательные мизансцены. Так, внушая женщинам страх, случайно задетое, начинает раскачиваться кресло-качалка, в котором сидела и отупело раскачивалась вперед-назад Минни Райт после того, как ее муж был найден мертвым. Применяя к анализу семиотический метод и рассматривая пьесу как аллегорию борьбы между старым и новым жизненными укладами, исследовательница Маковски замечает, что упоминание о качалке указывает на то, что Минни «раскачивалась между прошлым и будущим, без какого-либо прогресса» [9, p. 53]. Женщины выкладывают на столе потрепанные одежду и обувь заключенной, будто создавая ее безрадостный портрет.

В то время как женщины просматривают оставленные на кухне баночки с вареньем и подбирают одежду, «незаметно для людей входит Ужас» [10, с. 85], говоря словами В. Мейерхольда о «Вишневом саде» Чехова. Между делом оказывается, что дом Райтов находился на отшибе, а Джон Райт был человеком с тяжелым характером. Среди вещей подозреваемой обнаруживается лоскутное одеяло, последние лоскутки которого пришиты вызывающе криво и небрежно, что выдает душевную смуту и усталость. Потом находится птичья клетка со сломанной дверью, а потом и шкатулка с птицей со свернутой шеей (очевидно, это дело рук Джона Райта, которого вначале раздражало пение жены, а потом стало раздражать пение птицы). А ведь героиня, по словам одной из женщин, когда-то «сама была как птица хорошенькая, но при этом застенчивая и трепетная. Как она изменилась» [11, p. 20]. Нелишне заметить, что девичья фамилия Минни (Foster) переводится как «воспитывать, растить, заботиться», в то время как фамилия ее мужа (Wright) переводится как «мастер», иначе говоря, тот, кто доминирует, устанавливает свои правила. Вероника Маковски видит в фамилии Джона прежде всего созвучие глаголу «писа́ть», что может указывать на его желание «переписать» сценарий жизни Минни (см.: [9, р. 52]).

Собирая «мелочи» (а периодически мужчины спускаются со второго этажа и смеются над тем, какими пустяками заняты их жены), женщины практически находят улики против Минни Райт и воссоздают обстоятельства убийства. Но в то же время для них это неоспоримые свидетельства ее страдания, которое Минни совершенно в их глазах оправдывает. Женщины решают скрыть свои находки от 
мужей (вспомним, женская солидарность - частый мотив феминистской драматургии «Провинстаун плейерс»). Финал остается открытым.

Конфликт пьесы можно определить и как конфликт подлинного и мнимого, и как конфликт мужского и женского - именно к такой трактовке склоняются американские исследователи, для которых пьеса является иконой суфражизма (см.: [12; 8; 2]). Сьюзан Гласпелл, как и ее современники, была знакома с творчеством Хенрика Ибсена и Августа Стриндберга. И мы, безусловно, найдем здесь переклички с «Фрекен Жюли», с расстановкой сил в этой пьесе. Только главные антагонисты, не появляясь на сцене, предстают глазами сторонних наблюдателей - группы мужчин и группы женщин (подобная группа женских лиц без центра возникнет и в следующей пьесе Гласпелл - «Женская честь», где главная героиня так и не появится на сцене).

В контексте европейской «новой драмы» отсутствие не столько героини, сколько героя в пьесе «Мелочи» представляется особенно симптоматичным. В образе доминирующего, подавляющего мужского начала можно увидеть перекличку не только с Жаном Стриндберга, но и со всеми «отцами», чья власть не умаляется их физическим отсутствием на сцене, а постоянно напоминает о себе, подчеркивая хрупкость и уязвимость женского начала. Отец фрекен Жюли, отец Гедды Габлер, отец Норы, отец Ирины, Маши и Ольги - все они (кроме отца фрекен Жюли) мертвы, но их духовная власть над дочерьми подавляюще сильна. Чуть позднее в пьесе О’Нила «Странная интерлюдия» фигура собственного отца соединится в сознании главной героини - Нины Лидс - с фигурой эгоистичного и жестокого Бога Отца, не оставляющего в мире места для любви. Она воскликнет: «Мы должны представить жизнь как созданную Богиней Матерью. Тогда мы поймем, почему мы, Ее дети, получаем в наследство боль, мы будем осознавать, что наши жизни пульсируют в ритме Ее огромного сердца... И мы почувствуем, что смерть означает единение с Ней» [13, р.670].

Имя О’Нила возникает рядом с именем Гласпелл неслучайно. Своим ранним признанием (и О’Нил не раз отмечал это в своих письмах) он был обязан «Провинстаун плейерс». В 1916 г. в дом к Гласпелл и Куку был приглашен юноша, у которого, по слухам, был с собой «целый чемодан пьес». После того как пьеса «Курс на восток, в Кардифф» О’Нила была прочитана, ее немедленно приняли к постановке. Премьера спектакля «Курс на восток, в Кардифф» состоялась в театре на пристани 28 июля, премьера спектакля «Мелочи» - 8 августа того же 1916 г. Эти одноактные пьесы очевидным образом рифмуются друг с другом. Обе пьесы основаны на личном опыте авторов. Оба автора стремятся к вербальной дифференциации своих героев (пьеса О’Нила в этом смысле гораздо более радикальна). Обе пьесы - трагедии «несостоявшейся судьбы» [14, с.37].

Интересно то, что «чемодан пьес», принесенный угрюмым скитальцем О’Нилом, был чемоданом пьес о жизни моряков, «мужских пьес». Однако уже в 1917 г. (а О’Нил постоянно сотрудничал с «Провинстаун плейерс» - самым женским «малым театром» США) драматург создал пьесу «Китовый жир», где место действия все то же: борт корабля во время бесконечного и безрадостного плавания. Но на этот раз главной героиней являлась Анна, жена капитана китобойного судна мистера Кини (фанатика под стать Ахаву из «Моби Дика»), возвышенная натура, чей тонкий душевный мир не выдерживал мужской грубости и деспотизма. 
«Она убивает меня, эта жизнь: жестокость и холод, и ее ужас. <...> Я сойду с ума» $[15$, p. 80]. Через пару лет в творчестве драматурга на фоне моря возникла еще одна хрупкая женская фигура, еще одна Анна, и еще одна жертва патриархального устройства мира - Анна Кристи. В дальнейшем разрушенные женские судьбы оказались в центре важнейших пьес драматурга - «Крылья даны всем детям человеческим», «Странная интерлюдия», «Траур - участь Электры», «Долгое путешествие в ночь»...

Став первой в мире драматургической лабораторией, в которой творческая активность женщин не уступала активности коллег-мужчин, театр «Провинстаун плейерс» не только проторил тропу женщинам-драматургам - от Марши Норманн до Сьюзан Лори-Паркс, но и помог открыть новые грани творчества американским драматургам-мужчинам, по крайней мере, первому из них.

\section{Литература}

1. Станиславский К. С. Из письма к Вл. И. Немировичу-Данченко // Станиславский К. С. Собрание сочинений: В 9 т. М.: МХAТ, 1999. Т. 9.840 с.

2. Black C. The Women of Provincetown, 1915-1922. Tuscaloosa; London: The University of Alabama Press, 2002. 273 p.

3. Barlow J. Introduction // Women Writers of the Provincetown Players / ed. by J. Barlow. Albany; New York: State University of New York Press, 2009. 320 p.

4. Wainscott R. H. Staging O’Neill: The Experimental Years, 1920-1934. New Haven; London: Yale University Press, 1988. 384 p.

5. Glaspell S., Cook J.C. Suppressed Desires // The Provincetown Players. A Choice of the Shorter Works / ed. by B. Ozieblo. Sheffield: Sheffield Academic Press, 1994. 304 p.

6. Boyce N. Constancy // The Provincetown Players. A Choice of the Shorter Works / ed. by B. Ozieblo. Sheffield: Sheffield Academic Press, 1994. 304 p.

7. Glaspell S. The Road to The Temple. New York; Toronto: Frederick A. Stokes Company, 1941. 445 p.

8. Ben-Zvi L. "Murder, She Wrote": The Genesis of Susan Glaspell's "Trifles" // Susan Glaspell. Essays on Her Theater and Fiction / ed. by L. Ben-Zvi. Ann Arbor: University of Michigan Press, 1995. 360 p.

9. Makowsky V. Susan Glaspell and Modernism // The Cambridge Companion to American Women Playwrights / ed. by Brenda Murphy. Cambridge: Cambridge University Press, 1999. 324 p.

10. Мейерхольд В. Э. Статьи, письма, речи, беседы. М.: Искусство, 1968. Ч. 1. 351 с.

11. Glaspell S. Trifles. New York: Frank Shay, The Washington Square Players, 1916. 25 p.

12. Ozieblo B. Suppression and Society in Susan Glaspell's Theater // Susan Glaspell. Essays on Her Theater and Fiction / ed. by L. Ben-Zvi. Ann Arbor: University of Michigan Press, 1995. 360 p.

13. O’Neill E. Strange Interlude // O’Neill E. Complete Plays: In 3 vols. New York: The Library of America, 1988. Vol. 2. 1092 p.

14. Цимбал И.С. Театр Юджина О’Нила (1914-1924): дис. ... канд. искусствоведения. Л.: ЛГИТМиК, 1977. 176 с.

15. O’Neill E. Ile // O’Neill E. Early plays. New York: Penguin Books, 2001. 395 p.

Для цитирования: Клейман Ю. А. Театр «Провинстаун Плейерс» и генезис женской драматургии в США // Вестник СПбГУ. Искусствоведение. 2017. Т. 7. Вып. 3. С. 322-330.

DOI: $10.21638 / 11701 /$ spbu15.2017.303

\section{References}

1. Stanislavskii K.S. Iz pis'ma $\mathrm{k}$ Vl.I.Nemirovichu-Danchenko [From the letter to Vl. I. Nemirovich-Danchenko]. Stanislavskii K.S. Sobranie sochinenii: V 9 t. [Stanislavsky K. S. Complete works: 9 vols]. Moscow, MHAT, 1999, vol. 9.840 p. (In Russian)

2. Black C. The Women of Provincetown, 1915-1922. Tuscaloosa, London, The University of Alabama Press, 2002. 273 p.

3. Barlow J. Introduction. Women Writers of the Provincetown Players. Ed. by J. Barlow. Albany, New York, State University of New York Press, 2009. 320 p. 
4. Wainscott R.H. Staging O'Neill: The Experimental Years, 1920-1934. New Haven, London, Yale University Press, 1988. 384 p.

5. Glaspell S., Cook J.C. Suppressed Desires. The Provincetown Players. A Choice of the Shorter Works. Ed. by B. Ozieblo. Sheffield, Sheffield Academic Press, 1994. 304 p.

6. Boyce N. Constancy. The Provincetown Players. A Choice of the Shorter Works. Ed. by B. Ozieblo. Sheffield, Sheffield Academic Press, 1994. 304 p.

7. Glaspell S. The Road to The Temple. New York, Toronto, Frederick A.Stokes Company Publ., 1941. $445 \mathrm{p}$.

8. Ben-Zvi L. "Murder, She Wrote": The Genesis of Susan Glaspell's “Trifles". Susan Glaspell. Essays on Her Theater and Fiction. Ed. by L. Ben-Zvi. Ann Arbor, University of Michigan Press, 1995. 360 p.

9. Makowsky V. Susan Glaspell and Modernism. The Cambridge Companion to American Women Playwrights. Ed. by Brenda Murphy. Cambridge, Cambridge University Press, 1999. 324 p.

10. Meierkhol'd V.E. Stat'i, pis'ma, rechi, besedy [Articles, letters, reports, talks. Part 1]. Moscow, Iskusstvo, 1968. Part 1. 351 p. (In Russian)

11. Glaspell S. Trifles. New York: Frank Shay, The Washington Square Players, 1916. 25 p.

12. Ozieblo B. Suppression and Society in Susan Glaspell's Theater. Susan Glaspell. Essays on Her Theater and Fiction. Ed. by L. Ben-Zvi. Ann Arbor, University of Michigan Press, 1995. 360 p.

13. O’Neill E. Strange Interlude. O'Neill E. Complete Plays: In 3 vols. New York, The Library of America, 1988, vol.2. 1092 p.

14. Tsimbal I.S. Teatr Iudzhina O'Nila (1914-1924). Diss. ... kand. iskusstvovedeniia [Theatre of Eugene O’Neill (1914-1924). Diss. of PhD]. Leningrad, LGITMiK Publ., 1977. 176 p. (In Russian)

15. O’Neill E. Ile. O’Neill E. Early plays. New York, Penguin Books, 2001. 395 p.

For citation: Kleiman Yu. A. The Provincetown Players theatre and the genesis of women playwrights in the USA. Vestnik SPbSU. Arts, 2017, vol. 7, issue 3, pp. 322-330. DOI: 10.21638/11701/spbu15.2017.303

Статья поступила в редакцию 31 марта 2017 г.; принята в печать 25 мая 2017 г.

Контактная информация

Клейман Юлия Анатольевна - кандидат искусствоведения; spbgati@mail.ru

KleimanYulia A. — PhD; spbgati@mail.ru 